Recepción: 13/12/2018

Aceptación: 20/01/2019

Publicación: 05/03/2019

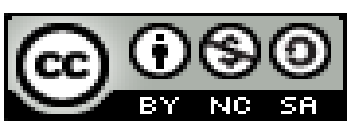

Ciencias Técnicas y Aplicadas Artículo de investigación

\title{
Efecto de los atrayentes semio-químicos en el control de la broca del fruto del café
}

\section{Effect of semi-chemical attractants in the control of the coffee fruit borer}

\section{Efeito de atrativos semi-químicos no controle da broca do café}

\author{
Richard Leonardo Palma-Ponce ${ }^{\mathrm{I}}$ \\ richard.palma@unesum.edu.ec \\ Jesús de los Santos Pinargote-Chóez II \\ jesus.pinargote@unesum.edu.ec \\ Tomás Robert Fuentes-Figueroa ${ }^{\text {III }}$ \\ tomas.fuentes@unesum.edu.ec
}

Correspondencia: richard.palma@unesum.edu.ec

I Magíster en Manejo y Aprovechamiento Forestal, Ingeniero Agrónomo, Docente de la Universidad Estatal del Sur de Manabí, Jipijapa, Manabí. Ecuador.

II Magíster en Administración Ambiental, Diplomado en Autoevaluación y Acreditación, Universitaria, Ingeniero Forestal, Docente de la Universidad Estatal del Sur de Manabí, Jipijapa, Manabí. Ecuador.

III Magíster en Gerencia Educativa, Diplomado en Autoevaluación y Acreditación Universitaria, Profesor de Segunda Enseñanza, Ingeniero Agropecuario, Docente de la Universidad Estatal del Sur de Manabí, Jipijapa, Manabí. Ecuador. 


\title{
Resumen
}

En los cafetales, la broca "Hypothenemus hampei Ferrari" es considerada la principal plaga, ya que deteriora la calidad del grano y disminuye la productividad, causando grandes pérdidas económicas. El manejo integrado de esta plaga incluye el control etológico, que consiste en la colocación de trampas artesanales, base de esta investigación. El trabajo se realizó en tres unidades de producción cafetalera de la zona sur manabita (cantones: Jipijapa 24 de Mayo y Paján), entre enero y septiembre de 2017. Se evaluaron dos difusores semio-químicos (3 partes alcohol metílico +1 parte alcohol etílico + café tostado y molido y Aguardiente + café tostado y molido). El experimento se condujo bajo un Diseño de Bloques al Azar, con 4 tratamientos y 3 repeticiones en cada localidad. En cada localidad (cafetal) se dispusieron 20 trampas a una distancia aproximada de $20 \times 20 \mathrm{~m}$. Cada quince días se registró el número de brocas capturadas, para el efecto se utilizó una tela lienzo filtrando el líquido (agua) lo cual facilitó la observación y conteo de las brocas, realizando el cambió del agua de las botellas. El porcentaje de infestación antes de las instalaciones de las trampas resultó 13,4\% (localidad 3); 8,9\% (localidad 1) y 4,38\% (localidad 2), disminuyendo el porcentaje cuando se instaló las trampas a 9,75\%; 10,8\% y 6,84\%, respectivamente. En todos los casos se registraron captura de brocas, no se evidenció diferencia estadística significativa entre los difusores; sin embargo, entre las localidades se registra diferencias significativas.

Palabras claves: café; broca; atrayentes; trampa; etológico.

\begin{abstract}
In the coffee plantations, the drill "Hypothenemus hampei Ferrari" is considered the main pest, as it deteriorates the quality of the grain and decreases productivity, causing great economic demands. The integrated management of this pest includes ethological control, which consists of the placement of artisanal traps, the basis of this research. The work was carried out in three coffee production units in the south Manabí area (cantons: Jipijapa 24 de Mayo and Paján), between January and September / 2017. Two semi-chemical diffusers were evaluated (3 parts methyl alcohol + 1 part ethyl alcohol + roasted and ground coffee and Aguardiente + roasted and ground coffee). The experiment was conducted under a randomized block design, with 4 treatments and 3 repetitions in each location. In each locality (coffee plantation), 20 traps were
\end{abstract}


placed at a distance of approximately $20 \times 20 \mathrm{~m}$. Every fortnight, the number of drill bits captured was recorded. For this purpose, a canvas cloth was used to filter the liquid (water), which facilitated the observation and counting of the drills, changing the water in the bottles. The percentage of infestation before the installation of the traps was 13.4\% (location 3); $8.9 \%$ (location 1) and 4.38\% (location 2), decreasing the percentage when the traps were installed at $9.75 ; 10.8 \%$ and $6.84 \%$, respectively. In all cases, bit capture was recorded, no significant statistical difference was found among the diffusers; However, significant differences are recorded between the localities.

Keywords: coffee; drill, attractive, trap, ethological

\section{Resumo}

Nos cafezais, a broca "Hypothenemus hampei Ferrari" é considerada a principal praga, pois deteriora a qualidade dos grãos e diminui a produtividade, causando grandes perdas econômicas. A gestão integrada desta praga inclui o controle etológico, que consiste na colocação de armadilhas artesanais, base desta pesquisa. $\mathrm{O}$ trabalho foi feito em três unidades de produção de café sul manabita (Cantones: jipijapa 24 de maio e Paján) entre Janeiro e Setembro de 2017. Semio dois difusores químicos (3 partes + álcool etílico álcool metílico uma parte foram avaliados + café torrado e moído e Aguardiente + café torrado e moído). O experimento foi conduzido em blocos ao acaso, com 4 tratamentos e 3 repetições em cada local. Em cada localidade (cafezal), 20 armadilhas foram colocadas a uma distância de aproximadamente 20 x 20 m. A cada quinzena foi registrado o número de brocas capturadas, para isso foi utilizado um pano de lona para filtrar o líquido (água), o que facilitou a observação e contagem das brocas, alterando a água das garrafas. A porcentagem de infestação antes da instalação das armadilhas foi de 13,4\% (local 3); 8,9\% (localização 1) e 4,38\% (localização 2), diminuindo a porcentagem quando as armadilhas foram instaladas em 9,75\%; 10,8\% e 6,84\%, respectivamente. Em todos os casos, a captura de bits foi registrada, não houve diferença estatística significativa entre os difusores; No entanto, diferenças significativas são registradas entre as localidades.

Palavras-chave: café; broca atrativos; armadilha etológico 


\section{Introducción}

La economía en Jipijapa está ligada a la caficultura, cultivo tradicional que se desarrolla bajos sistemas de policultivos agroforestales con aproximadamente 12.000 hectáreas cultivadas. El principal problema del sector cafetalero en esta importante zona, sigue siendo la baja productividad por unidad de superficie y la deteriorada calidad del grano causado entre otros factores por el comportamiento errático del clima, manejo inadecuado de los sistemas agroforestales en base del cultivo de café y la falta de diseminación de alternativas tecnológicas para el control fitosanitario.

Hipothenemus hampei Ferr., es la principal plaga de los cafetos en todos los países productores del grano; fue descrita por primera vez por el entomólogo austriaco Ferrari en 1867, y en 1903 comenzó a convertirse en una plaga de importancia en los países de África ecuatorial (Fernández y Cordero, 2007). En Ecuador los primeros reportes de H. hampei F, se realizan en 1981 en la provincia de Zamora Chinchipe, hacia el cantón Chinchipe, luego se dispersó a otras zonas cafetaleras de esta provincia. Posteriormente, se localiza en otras áreas cafetaleras de las provincias de Loja, El Oro, Santo Domingo de los Tsachilas, Manabí y Napo, con niveles de infestación que alcanzaron hasta el 85 por ciento (Tandazo, et al., 1997).

Las hembras perforan el fruto y depositan entre 12 a 30 huevos/grano, luego abandonan el grano y continúan ovipositando en otros frutos sanos, mermando su peso y deteriorando su calidad (Acacio y Gil, 2013). Es necesario realizar un control de H. hampei F., que sea amigable al medio ambiente. El control etológico consiste en el trampeo (trampa + atrayente) y permite capturar la broca que se encuentra volando durante su fase de migración. Las trampas se recomiendan instalarlas aproximadamente 90 días después de la floración y se recogen después de la cosecha (PROMECAFE, 2007).

Este tipo de control es una estrategia de fácil adopción y bajo costo para los caficultores, además, es una forma de monitorear y controlar este insecto plaga, los resultados obtenidos del estudio permitirán mejorar la productividad por unidad de superficie e incrementar la calidad del grano, ya que redundara de manera efectiva en el control de la plaga e impactara de manera positiva en el sector caficultor, potenciando La economía en Jipijapa. 
La investigación se orientó a determinar el efecto de los atrayentes semio-químicos en el control de H. hampei (broca del café), en los cantones de Jipijapa, Paján y 24 de mayo.

\section{Materiales y Métodos}

La investigación se realizó en el año 2017, en tres unidades producción cafetalera ubicadas en los cantones: Paján, 24 de Mayo y Jipijapa de la provincia de Manabí, este estudio tuvo como propósito describir el efecto de los atrayentes semio-químicos en el control de H. hampei (broca del café) en los cantones de Jipijapa, Paján y 24 de Mayo. En la Tabla 1, se detalla la ubicación de los lotes experimentales.

\section{Tabla 1.}

Ubicación de los ensayos de la investigación "Efecto de los atrayentes semio-químicos en el control de la broca del fruto del café "Hypothenemus hampei Ferr"

\begin{tabular}{ccccc}
\hline Localidad & \multicolumn{2}{c}{ Coordenadas UTM } & \multicolumn{2}{c}{ Ubicación } \\
& $\mathrm{X}$ & $\mathrm{Y}$ & Sitio & Cantón \\
\hline 1 & 567633 & 982490 & Campozano & Paján \\
2 & 567092 & 984806 & Los Ángeles & Je Mayo \\
3 & 553000 & 983737 & El Descanso & Jipijapa \\
\hline
\end{tabular}

\section{Fuente: Elaboración Propia}

Para la construcción de las trampas se usaron botellas vacías de 3000ml, frascos de $100 \mathrm{ml}$ y 200 $\mathrm{ml}$, de plástico, agua, estilete, cinta adhesiva y alambre (Duicela, 2011).

Materiales para difusor. - Café tostado y molido, alcohol metílico, alcohol etílico, agua ardiente.

Preparación difusor 1. - En las tapas de los frascos de plástico de $100 \mathrm{ml}$ y $200 \mathrm{ml}$ se realizó una pequeña abertura para gasificar, se colocó de 60 g y 100 g de café tostado y molido con una mezcla de los alcoholes: metílico (tres partes) y etílico (una parte), según lo descrito por PROMECAFÉ (2007).

Preparación difusor 2. - En las tapas de los frascos de plástico de $100 \mathrm{ml}$ y $200 \mathrm{ml}$ se realizó una pequeña abertura para gasificar, se coloca $80 \mathrm{ml} \mathrm{y} 100 \mathrm{ml}$ obtenido de la mezcla (1 litro de aguardiente + café tostado y molido). 
El experimento se condujo bajo un Diseño de Bloques al Azar, con cuatro tratamientos (T1: 3 parte de alcohol metílico +1 de alcohol etílico + frasco de 100. T2: 3 parte de alcohol metílico + 1 de alcohol etílico + frasco de 200. T3: 0,5 medio aguardiente + café tostado molido + frasco de 100. T4: $1 / 2$ medio aguardiente + café tostado molido + frasco de 200) y tres repeticiones en cada localidad. En cada lote de cafetal se dispusieron cuatro trampas por tratamiento (Difusor); es decir, 20 trampas/lote, a una distancia aproximada de $20 \mathrm{~m}$ x $20 \mathrm{~m}$. Se monitoreo cada quince días para registrar el número de brocas capturadas en las trampas ubicadas en el campo, entre junio y agosto/2017.

Se realizó un análisis de varianza mediante la prueba de tukey al $\mathrm{p}<0,05$, realizando la transformación de los datos al valor logarítmico log $\mathrm{X}+25$, para su normalización, debido a que los datos originales no siguen una distribución normal. La comparación de medias del número de brocas capturadas/trampa, se realizó mediante el análisis de comparaciones ortogonales.

\section{Resultados y Discusión}

\section{1.- Porcentaje de infestación}

El porcentaje de infestación de H. hampei F., durante los primeros cinco meses del 2017 se registraron valores porcentuales $<1,0$ en las fincas evaluadas, mientras que en el segundo semestre se registró un incremento, llegando a su punto máximo en el mes de julio en todas las localidades. La localidad 3 (El Descanso-Jipijapa) registró el mayor porcentaje de infestación (13,45\%), en las otras localidades 1(Campozano-Paján) y 2 (Los Ángeles-24 de Mayo) presentaron porcentajes de infestación de 6,2 y 4,8 respectivamente. Las trampas fueron colocadas en el mes de julio, evidenciándose al siguiente monitoreo una disminución en el porcentaje de infestación: La localidad 3 (8,7\%); localidades $1(3,8 \%)$ y localidad $2(1,26 \%)$. En la Figura 1, se presentan el porcentaje de infestación de H. hampei registrados durante la ejecución del estudio. 


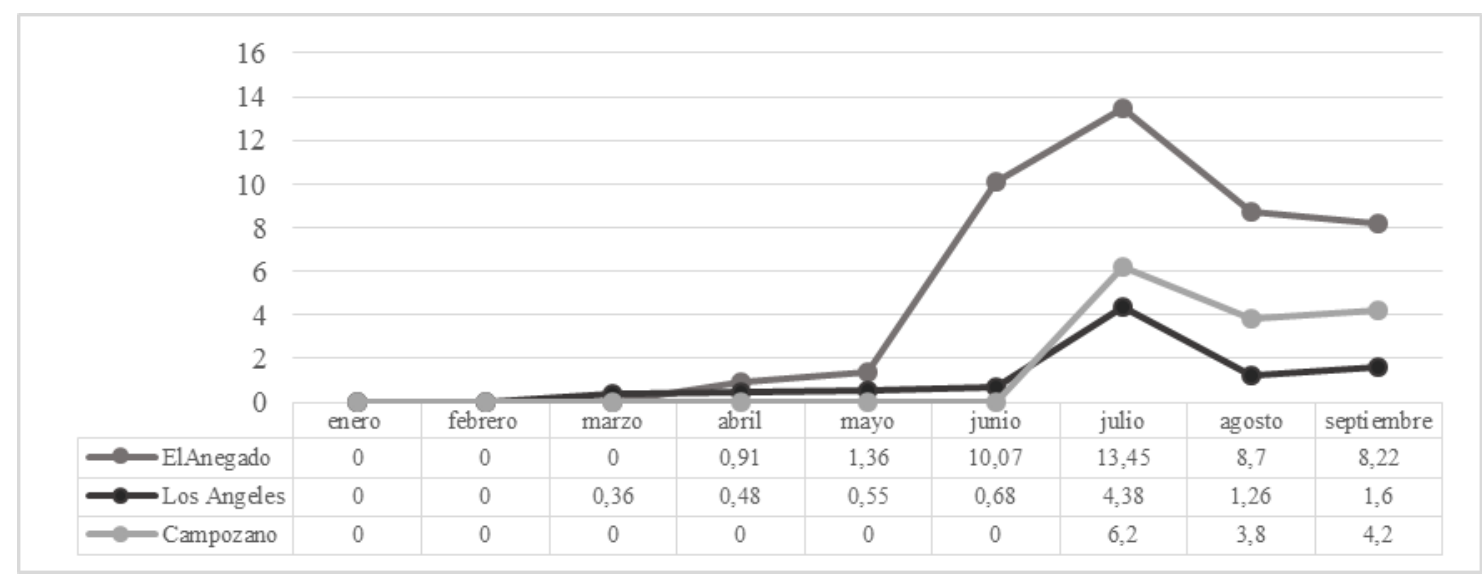

Figura 1.- Porcentaje de infestación de broca en los ensayos de control etológico

\section{2. - Efecto de los difusores en relación al número de brocas capturadas/trampa}

Los cuadrados medios, significación estadística y coeficientes de variación del número de individuos capturados/trampa a los 15, 30, 45 y 60, días después de la instalación (ddi) de las trampas; así como, del total de individuos capturados, en plantaciones de café arábigo se indican en la Tabla 2.

El análisis de varianza permitió establecer que no existe diferencias estadísticas significativas $(\mathrm{p}<0,05)$ cuando se analizó el número de individuos capturados por cada evaluación; sin embargo, cuando se realizó el análisis entre el número de individuos capturados y las localidades se registró diferencia estadística al p $>0,05$ en la localidad 1 con respecto a las localidades 2 y 3. En el empleo de los diferentes tipos de difusores para la captura de la broca del café, tampoco se registró significación estadística $(\mathrm{p}<0,05)$ durante los días evaluados.

La respuesta olfativa de $\mathrm{H}$. hampei a sustancias volátiles provenientes del fruto es evidenciada por la parada del insecto al interceptar el flujo de olor, girando y caminando en dirección a la fuente del olor (Mendoza, 1991). En la tabla 2, se presenta los cuadrados medios y coeficiente de correlación referente al número de individuos capturados.

Pol. Con. (Edición núm. 31) Vol. 4, No 3, marzo 2019, pp. 46-60, ISSN: 2550 - 682X 


\section{Tabla 2.}

Cuadrados medios (CM), significación estadística (SE) y coeficientes de variación del número de individuos capturados con dos tipos de difusores, en las tres fincas evaluada.

\begin{tabular}{|c|c|c|c|c|c|c|c|c|c|c|c|c|}
\hline \multirow{2}{*}{ Fuente de variación } & \multirow{2}{*}{$\begin{array}{l}\text { Grados } \\
\text { libertad }\end{array}$} & \multirow[t]{2}{*}{ de } & \multicolumn{2}{|l|}{15 DDI } & \multicolumn{2}{|l|}{30 DDI } & \multicolumn{2}{|c|}{45 DDI } & \multicolumn{2}{|l|}{60 DDI } & \multicolumn{2}{|l|}{ Total } \\
\hline & & & CM & SE & CM & SE & CM & SE & CM & SE & CM & $\mathbf{S E}$ \\
\hline Localidades & 2 & & 0,004 & NS & 0,017 & NS & 0,003 & NS & 0,013 & NS & 0,008 & * \\
\hline Tratamientos & 3 & & 0,008 & NS & 0,0025 & NS & 0,006 & NS & 0,0023 & NS & 0,010 & NS \\
\hline Error Experimental & 6 & & 0,002 & & 0,0073 & & 0,003 & & 0,010 & & 0,008 & \\
\hline \multicolumn{2}{|c|}{ Coeficiente de variación (\%) } & & 2,82 & & 5,28 & & 2,98 & & 6,33 & & 4,29 & \\
\hline
\end{tabular}

$\mathrm{NS}=$ No existen diferencias estadísticamente significativas $(\mathrm{P}>0,05)$

* $=$ Existen diferencias estadísticas significativas $(\mathrm{P}<0,05)$

Fuentes: Elaboración propia

El análisis de varianza mediante la prueba de tukey al p-0,05 se determinó diferencia estadística en el número de brocas capturada entre localidades. Siendo las trampas ubicada en la localidad uno (1) la que registró el mayor número de brocas capturadas. En la Tabla 3, se presenta el número de capturas realizadas durante 60 días evaluados

Fernández y Cordero (2005), en un estudio realizado en Venezuela, sobre atrayentes con alcohol en trampas artesanales para el monitoreo y control de la broca de café determinaron que las mejores proporciones de mezcla de alcohol, en cuanto a la respuesta de captura de adultos fueron: metílico + etílico (proporción de 3:1), etílico + metílico (1:1), y etílico + metílico + café molido (1:1:1), obteniendo capturas entre 4017 y 426 individuos por semana.

En un estudio realizado por García et al., (2005), en Venezuela, donde evaluaron alternativas de atrayentes de la $\mathrm{H}$. hampei, determinaron que los alcoholes combinados Etanol + Metanol (proporción 3:1) mostraron mayor eficiencia como atrayentes para captura de broca del café en las trampas artesanales, que lograron capturas de 3.190 individuos/trampa/30 días. Mientras que en el presente estudio se capturaron 1561 adultos de H. hampei

La evaluación de atrayentes para la captura de hembras adultas de H. hampei con trampas artesanales, realizada en Cuba, por Moreno et al., (2010), establecieron que la mezcla de metanol + etanol (3:1) resultó la más efectiva, en contraste con el alcohol etílico solo y el alcohol etílico mezclado con café tostado molido, que capturaron menor número de adultos. 
Los datos obtenidos en la presente investigación, coinciden en dos localidades con los trabajos reportados por Moreno et al., (2010) en relación a que el mejor atrayente resultó la combinación 3:1 de alcohol metílico y alcohol etílico.

El reporte de Fernández y Cordero (2005), coincide con el presente estudio en relación con la eficiencia de los atrayentes que incluyen café tostado y molido en la preparación.

Tabla 3

Análisis de medias de individuos capturados de H. hampei F. por localidad. Tukey 0,05\%

\begin{tabular}{cccc}
\hline Localidades & Medias & $\mathbf{n}$ & EE \\
\hline 2 & 1,91 & 5 & $0,05^{\mathrm{a}}$ \\
3 & 1,65 & 5 & $0,05^{\mathrm{b}}$ \\
1 & 1,45 & 5 & $0,05^{\mathrm{c}}$ \\
\hline
\end{tabular}

n: números de datos que se repiten; E.E: significación;

Medias con una letra común no son significativamente diferentes $(p>0,05)$

Fuente: Elaboración Propia

\section{3.- Captura de adultos de individuos/trampa a nivel de las localidades}

En la localidad de Paján se registró el mayor número de capturas. En las localidades 3 y 1 el difusor 1, compuesto por: tres partes de alcohol metílico + una de alcohol etílico $+10 \mathrm{~g}$ de café tostado y molido en frasco de $100 \mathrm{ml}$., resultaron ser más eficientes en la captura de broca. Mientras que en la localidad 2 el difusor 2, compuesto por $0,5 \%$ de aguardiente más $10 \mathrm{~g}$ de café tostado y molido H. hampei, registró el mayor número de capturas al final de las evaluaciones (Tabla 4).

La captura de la broca mediante el uso de trampas está influenciada por parámetros ambientales como la humedad relativa, temperatura y luminosidad, a menor intensidad de luz, mayor es la captura. El trampeo dirigido sobre áreas sombreadas en el cafetal puede incrementar la eficacia de la captura de broca. Por otro lado, las condiciones climáticas óptimas de humedad relativa, temperatura y precipitación; así como el sombreado excesivo de los cafetales, permiten a la broca sobrevivir y desarrollarse con más facilidad (Solórzano 2004). 
Tabla 4.

Número de individuos capturados por trampas y tratamiento, en las localidades (fincas) evaluadas.

\begin{tabular}{cccc}
\hline Tratamiento & Paján & 24 de Mayo & Jipijapa \\
\hline 3M1E+Cf-100 & 375 & 205 & 258 \\
3M1E+Cf-200 & 354 & 137 & 232 \\
$0,5 \%$ Agua Ard.+Cf-100 & 307 & 119 & 177 \\
$0,5 \%$ Agua Ard.+Cf-200 & 303 & 244 & 158 \\
Total & $\mathbf{1 3 3 9}$ & $\mathbf{7 0 5}$ & $\mathbf{8 2 5}$ \\
\hline
\end{tabular}

3M1E+Cf100: 3 parte de alcohol metílico + 1 de alcohol etílico + frasco de 100. 3M1E+Cf200: 3 parte de alcohol metílico + 1 de alcohol etílico + frasco de 200; 0,5\%Agua Ard. +Cf-100: 1/2 medio aguardiente + café tostado molido+ frasco de 100; 0,5\%Agua Ard. + Cf-200: $1 / 2$ medio aguardiente + café tostado molido + frasco de 200

Fuente: Elaboración propia

El análisis de comparaciones ortogonales, permitió confirmar que no existe significación estadística entre los difusores, esto significa que todos los difusores: 3 parte de alcohol metílico + 1 de alcohol etílico y, medio aguardiente + café tostado molido, capturaron individuos adultos aun cuando el porcentaje de infestación era bajo (Tabla 5).

\section{Tabla 5.}

Comparaciones ortogonales del efecto de los difusores, semioquímicos en la captura de broca en trampas artesanales

\begin{tabular}{|c|c|c|c|c|c|c|c|c|c|c|c|c|c|}
\hline Comparación & $\begin{array}{l}\text { T1 } \\
21\end{array}$ & $\begin{array}{l}2 \\
16\end{array}$ & $\begin{array}{l}\text { T3 } \\
15\end{array}$ & $\begin{array}{l}\text { T4 } \\
15\end{array}$ & $\mathbf{r}$ & $\mathbf{k}$ & rk & $\mathbf{Q}$ & $\mathbf{C M}$ & F calculada & SE & $\begin{array}{c}\mathbf{F} \\
\mathbf{0 , 0 5}\end{array}$ & $\begin{array}{c}\mathbf{F} \\
\mathbf{0 , 0 1}\end{array}$ \\
\hline $\mathrm{C} 1$ & 2 & 2 & -2 & -2 & 3 & 16 & 48 & 13,056 & 3,551 & 3,06 & NS & 6,2 & 15,2 \\
\hline $\mathrm{C} 2$ & 1 & -1 & & & 3 & 2 & 6 & 4,3611 & 3,170 & 2,73 & NS & & \\
\hline $\mathrm{C} 3$ & & 1 & -1 & & 3 & 2 & 6 & 1,1389 & 0,216 & 0,19 & NS & & \\
\hline $\mathrm{C} 4$ & & & 1 & -1 & 3 & 2 & 6 & $-0,1111$ & 0,002 & 0,00 & NS & & \\
\hline
\end{tabular}

T1: 3 parte de alcohol metílico +1 de alcohol etílico + frasco de 100. T2: 3 parte de alcohol metílico + 1 de alcohol etílico + frasco de 200. T3: 1/2 medio aguardiente + café tostado molido+ frasco de 100. T4: $1 / 2$ medio aguardiente + café tostado molido+ frasco de 200; K: sumatoria de os coeficiente de comparación al cuadrado; Q: sumatoria de los productos tratamientos X coeficiente: contrate lineal; CM. Cuadrado medio; SE Significación estadística.

Fuente: Elaboración propia

Los difusores que en su preparación tienen granos tostados y molidos son más efectivos que los difusores sin café para la captura de adultos durante el periodo de evaluación en las fincas. Este comportamiento puede deberse al olor intenso que desprende el café tostado y molido, lo cual favorece la eficacia del difusor como atrayente de la broca. Respecto a la adición de café tostado molido, se han reportado efectos importantes de sinergismo entre la mezcla de alcoholes metílico y etílico con café soluble (Moreno et al., 2010). 


\section{4.- Costos de la elaboración e instalación de trampas artesanales para el control de la broca del café}

Los costos de elaboración e instalación de trampas artesanales para el establecimiento en una ha de café en función de los difusores evaluados en las fincas, se presenta en la tabla 6. El cálculo se realizó considerando cuatro cambios de difusor durante el año cafetalero, con 20 trampas/ha. Los costos del trampeo varían en función de los insumos con que están preparados los difusores.

\section{Tabla 6.}

Costos de elaboración e instalación de trampas artesanales para el control de broca en 1 ha de café

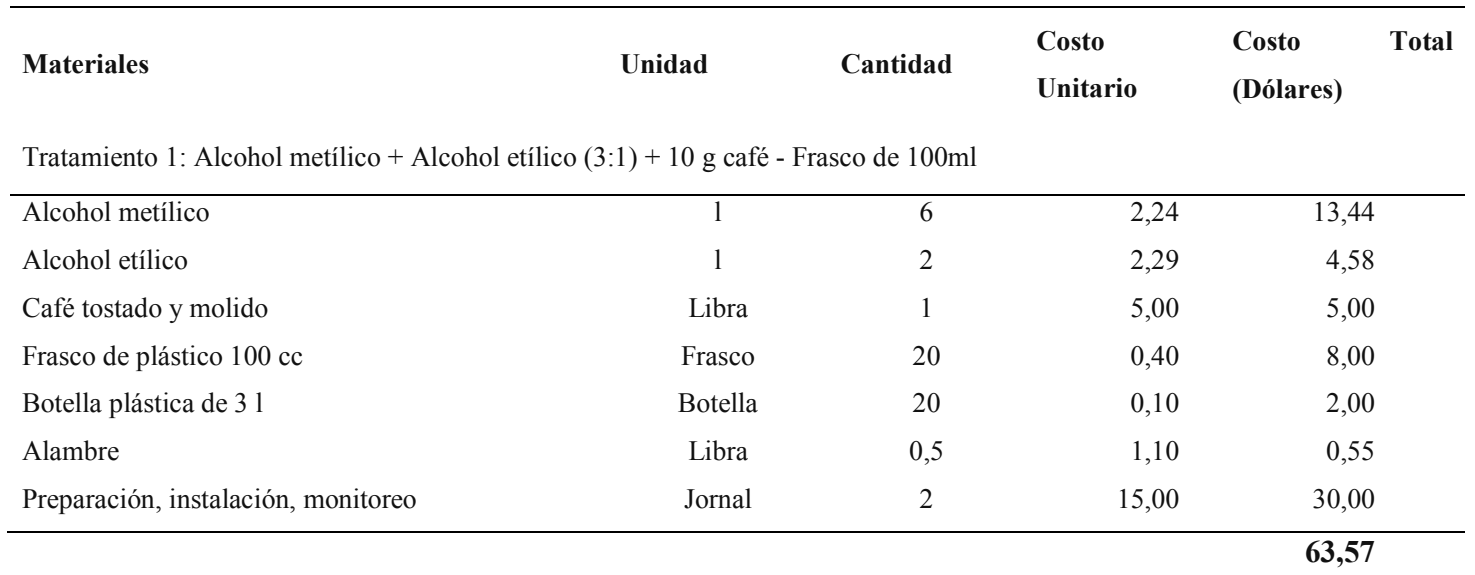

Fuente: Elaboración propia

Tabla 7.

Costos de elaboración e instalación de trampas artesanales para el control de broca en 1 ha de café

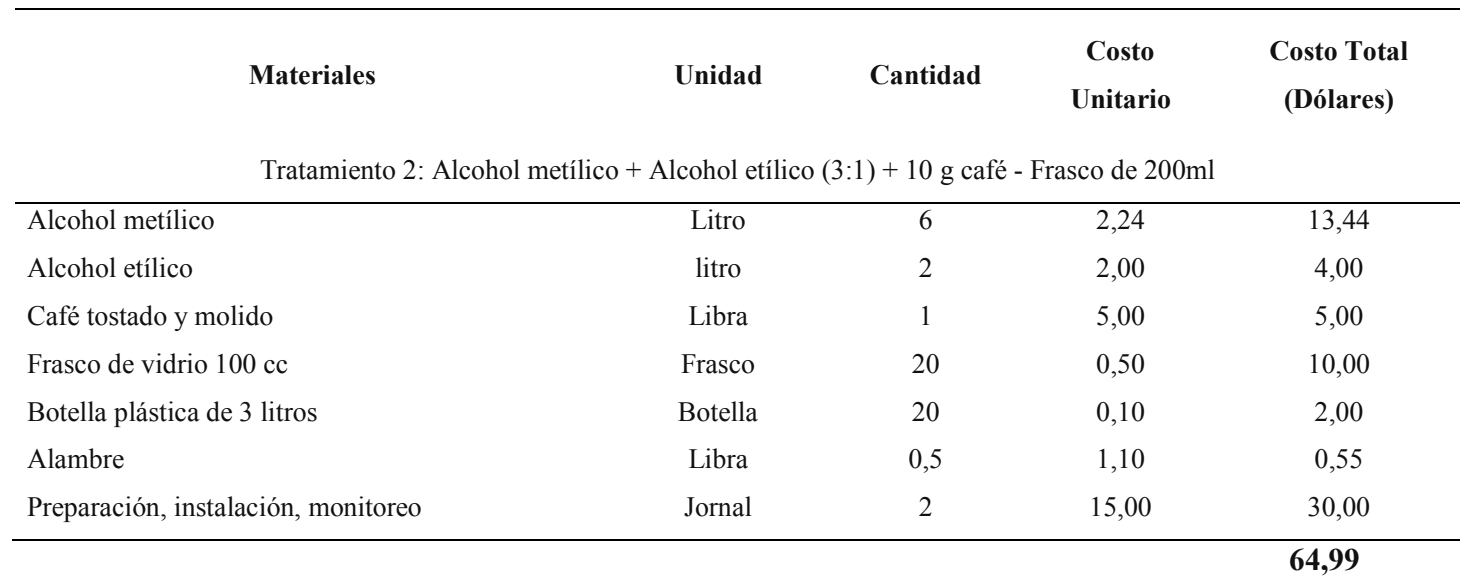

Fuente: Elaboración propia

Pol. Con. (Edición núm. 31) Vol. 4, No 3, marzo 2019, pp. 46-60, ISSN: 2550 - 682X 
Richard Leonardo Palma Ponce, Jesús de los Santos Pinargote Chóez, Tomás Robert Fuentes Figueroa

Tabla 8.

Costos de elaboración e instalación de trampas artesanales para el control de broca en 1 ha de café

\begin{tabular}{lcccc}
\hline Materiales & Unidad & Cantidad & $\begin{array}{l}\text { Costo } \\
\text { Unitario }\end{array}$ & $\begin{array}{l}\text { Costo } \\
\text { (Dólares) }\end{array}$ \\
Tratamiento 3: Aguardiente $+10 \mathrm{~g}$ café- frasco de $100 \mathrm{ml}$ & & & \\
\hline Agua ardiente & Litro & 8 & 3,00 & 24,00 \\
Café tostado y molido & Libra & 1 & 5,00 & 5,00 \\
Frasco de vidrio 100 cc & Frasco & 20 & 0,40 & 8,00 \\
Botella plástica de 3 litros & Botella & 20 & 0,10 & 2,00 \\
Alambre & Libra & 0,5 & 1,10 & 0,55 \\
Preparación, instalación, monitoreo & Jornal & 2 & 15,00 & 30,00 \\
\hline
\end{tabular}

Fuente: Elaboración propia

Tabla 9.

Costos de elaboración e instalación de trampas artesanales para el control de broca en una hectárea de café

\begin{tabular}{lllll}
\hline Materiales & Unidad & Cantidad & $\begin{array}{l}\text { Costo } \\
\text { Unitario }\end{array}$ & $\begin{array}{l}\text { Costo } \\
\text { (Dólares) }\end{array}$ \\
Tratamiento 3: Aguardiente $+10 \mathrm{~g}$ café- frasco de $200 \mathrm{ml}$ & & & \\
\hline Agua ardiente & Litro & 8 & 3,00 & 24,00 \\
Café tostado y molido & Libra & 1 & 5,00 & 5,00 \\
Frasco de vidrio 200 cc & Frasco & 20 & 0,50 & 10,00 \\
Botella plástica de 3 litros & Botella & 20 & 0,10 & 2,00 \\
Alambre & Libra & 0,5 & 1,10 & 0,55 \\
Preparación, instalación, monitoreo & Jornal & 2 & 15,00 & 30,00 \\
\hline
\end{tabular}

Fuente: Elaboración propia

\section{Conclusiones}

Los resultados del estudio de "Efecto de los atrayentes semio-químicos en el control de la broca del fruto del café (Hypothenemus hampei Ferr)", permitieron establecer las siguientes conclusiones:

- El porcentaje de infestación de H hampei, disminuye cuando se realiza el control etológico con trampas artesanales y difusores a base de alcoholes + café. Además, las trampas siguen capturando aun cuando ya no existe granos en los cafetos (luego de la cosecha). 
- Cuando se realizó el análisis de varianza entre tratamientos; así como entre difusores no se registraron diferencias estadísticas en ninguno de los casos. De igual manera cuando se realizó comparaciones ortogonales entre tratamientos.

- La captura individuos adultos con las trampas artesanales no se limita a la presencia de frutos en los cafetos, se extiende incluso luego de la cosecha, capturando las brocas que emergen de los frutos caídos en el suelo o de los frutos remanentes en los cafetos.

- Los costos del control etológico varían en función de los insumos con que están preparados los difusores y varían entre 63,57 y 70,55 dólares/ha. El uso de trampas artesanales se presenta como una alternativa de bajo costo, siendo factible de utilizarse por los caficultores en los programas de Manejo Integrado de $\mathrm{H}$ hampei.

\section{Recomendaciones}

- Seguir monitoreando las trampas y verificar la captura de brocas aun sin tener presencia de café, en el propósito de seguir disminuyendo el porcentaje de infestación y contribuir al mejoramiento de la calidad y productividad de los cafetales.

- Evaluar otros tipos de atrayentes y compararlos con los evaluados en la presente investigación

- Una vez con los resultados definitivos, diseminar la información entre los productores para la rápida adopción del control etológico estudiados en los cantones del sur de Manabí y su área de influencia.

\section{Referencias Bibliográficas}

Acacio, G. y Gil, J. (2013). Efecto del color de trampa en la captura de la broca del café (Hypothenemus hampei Ferr.) en tres localidades de Tingo María. Investigación y Amazonía 2012; 2 (1-2): 27-34. Recuperado de http://www.unas.edu.pe/revistas/index.php/revia/article/view/26

Duicela Guambi, LA. (2011). Manejo sostenible de las fincas cafetaleras. Buenas prácticas en la producción de café arábigo y gestión de la calidad en las organizaciones de productores. Portoviejo, EC. COFENAC, ANECAFE, CFC, ICO. P. 43-142. 
Férnandez, S y Cordero. (2005). Evaluación de atrayentes alcoholicos en trampas artesanales para el monitoreo y control de la broca del café, Hypothenemus hampei (Ferrari). Bioagro 17(3):143-148.2005. Venezuela. Consultado el 08 de octubre de 2017. Recuperado de http://redalyc.uaemex.mx/pdf/857/85717303.pdf

Fernández, S y Cordero, J. (2007). Biología de la broca del café Hypothenemus hampei (Ferrari) (Coleóptera: Curculionidae: Scolytinae) en condiciones de laboratorio (en línea). Venezuela. Biagro. Consultado 8 de octubre de 2017. Recuperado de http://redalyc.uaemex.mx/pdf/857/85719105.pdf

García, R; Riera, R; Rondón, J; Contreras, M; Moncada, N; Rojas, E. (2005). Evaluación de alternativas como atrayentes alcohólicos de la broca del café Hypothenemus hampei dispuestos en trampas artesanales, en Mesa Las Palmas del Estado Mérida (en línea). Venezuela. Instituto Nacional de Investigaciones Agrícolas. INIA. Consultado 23 enero 2012. Recuperado de http://cires.org.ve/pdf/agroalimentacion-n7a03.pdf ( $N^{\text {o }} 7$ Art. 3).

Mendoza, J. R. (1991). Resposta da broca-do-cafe, Hypothenemus hampei, a estimulos visuais e semioquímicos. Tesis Mag. Sc. Minas Gerais, BR, Universidade Federal de Viçosa. 44 p.

Moreno, D; Álvarez, A; Vázquez, L; Simonetti, J. (2010). Evaluación de atrayentes para la captura de hembras adultas de broca del café hypothenemus hampei (ferrari) con trampas artesanales (en línea). Habana, Cuba, Instituto de Investigaciones de Sanidad Vegetal. Consultado 23 enero 2012. Recuperado de http://scielo.sld.cu/scielo.php?pid=S156230092010000300005\&script $=$ sci_arttext

PROMECAFÉ (Programa Cooperativo Regional para el Desarrollo Tecnológico y Modernización de la Caficultura en Centroamérica, Panamá, República Dominicana y Jamaica). (2007). Manejo Integrado de la broca del café diseñado con tres componentes (en línea). IICA. Consultado 8 de octubre de 2017. Recuperado de http://www.iica.org.gt/promecafe/boletines/mib/boletin2_mib.pdf

Solórzano, J. (2004). Color, tipo de trampas y tipos de señuelo para la captura de la broca del café (Hypothenemus hampei) Ferrari (Coleptera: Curculionidae: Scolitynae en Costa Rica (en línea). Colegio de Posgrado. Institución de Enseñanza e Investigación en Ciencias 
Agrícolas. Instituto de Fitosanidad. Maestría Tecnológica en Medidas Sanitarías y Fitosanitarías. Consultado 12 octubre 2017. Recuperado de http://www.oirsa.org/aplicaciones/subidoarchivos/BibliotecaVirtual/CostaRicaTesinaTra mpasRoyaCafe.pdf

Tandazo A; Cisneros P; Jaramillo T; Espinoza O. (1997). Control integrado de la broca del café en la región sur del país. Servicio Ecuatoriano de Sanidad Agropecuaria. Dirección Provincial Agropecuaria de Loja, Ministerio de Agricultura y Ganadería, Programa de apoyo alimentario USAID PL-480. 144 p. Loja-Ecuador 